\title{
Epidemiology of Periodontal Disease among the Elderly
}

\begin{abstract}
The present study aims to reflect on the oral health status of the elderly, addressing periodontal disease, as well as the importance of oral health general health and quality of life. The methodology adopted consisted of a bibliographic research of scientific articles indexed in PUBMED® and Google Scholar® with the following combined keywords: "Periodonta Disease", "Gerodontology", "Oral Health", "Elderly" and "Epidemiology", either in Portuguese or in English. The exclusion criteria for the selection of the scientific articles used consisted in limiting the research to the Portuguese and English languages, limiting the publication date to the last 10 years, and only scientific articles referring to the epidemiology of periodontal disease among the elderly. Therefore, from a total of 33 scientific articles, only 17 scientific articles were selected for the present research. The most recent studies do show that periodontal disease is clearly a public health issue, increasing among all ages. However, this oral pathology should be carefully analyzed among the elderly considering the higher risk of association with the development of other systemic diseases and also the physiological, mental and social changes that characterize this specific age group.
\end{abstract}

\section{Introduction}

In developed countries, the elder is considered an individual aged 65 or over. However, some authors do not have in consideration this classification because they consider that there is a high variability regarding physical, mental, psycho-social and medical conditions. Thus, they defend an individual analysis based in the characterization of the individual's level of independency: independent, debilitated or functionally dependent [1].

According to research developed in Finland and the United States of America, the majority of the elderly, accounting for approximately 90-95\%, are independent and live in a normal basis in their own community. Thus, about 5 to $10 \%$ of the elderly are functionally dependent, and these require continuous health care, and this prevalence increases with age. In 2001, a study was developed in Portugal by the National Institute of Health Dr. Ricardo Jorge, which demonstrated the existence of $8.3 \%$ of functionally dependent elderly, of whom $92.5 \%$ obtain almost daily help [1]. Currently, the elderly do seek oral health care more frequently than previously, but oral pathology still presents a high prevalence among the Portuguese population [1].

The World Health Organization (WHO) predicts that by 2025 there will be 1.2 billion people over the age of 60 [2]. In this way, with the increase in the average life expectancy and the improvement of social conditions, a natural dentition should last and be preserved for a longer period of time, as well as a reduction of oral pathologies in the elderly is necessary in order to improve their quality of life. However, the prevalence of these same pathologies continues to be significant, with dental caries and periodontal disease being the most common diseases [3].

These pathologies are not directly associated with the effect of increasing age, but they cannot be dissociated from the state of general health, since they are usually patients with other systemic

\section{Journal of Oral Biology}

\author{
Nélio Veiga ${ }^{1,2 *}$, Carla Monteiro ${ }^{1}$, Catarina Couto ${ }^{1}$, \\ Diogo Silva ${ }^{1}$, Luís Clemente ${ }^{1}$, Rita Costa ${ }^{1}$, Manuel \\ de Sousa ${ }^{1}$, Tiago Marques ${ }^{1}$, Susana Silva ${ }^{1}$ and \\ Carlos Pereira ${ }^{3}$ \\ ${ }^{1}$ Health Sciences Institute - Universidade Católica Portuguesa, \\ Portugal \\ ${ }^{2}$ Centre for Interdisciplinary Research in Health (CIIS) \\ Universidade Católica Portuguesa, Portugal \\ ${ }^{3}$ CI\&DETS, Polytechnic Institute of Viseu, Portugal
}

*Address for Correspondence

Nélio Veiga, Health Sciences Institute, Universidade Católica Portuguesa, Estrada da Circunvalação, 3504-505, Viseu, Portugal, Tel: 00351 966454933; Email: nelioveiga@gmail.com

Submission: 29 August, 2017

Accepted: 30 September, 2017

Published: 09 October, 2017

Copyright: () 2017 Veiga N, et al. This is an open access article distributed under the Creative Commons Attribution License, which permits unrestricted use, distribution, and reproduction in any medium, provided the original work is properly cited.

diseases and highly polymedicated.

Periodontal disease is one of the most common chronic diseases with a variance of 10 to $60 \%$ in adults depending on the diagnostic criteria [4]. It is difficult to perform the epidemiological interpretation of periodontal data due to the inconsistency of the methodology used [5]. In general, the individual is considered to be periodontally compromised when presenting a minimum attachment loss of $3 \mathrm{~mm}$ and minimal periodontal pockets of $4 \mathrm{~mm}[4,5]$.

Moderate periodontal disease is defined as having at least 2 teeth with loss of interproximal attachement of $4 \mathrm{~mm}$ or more or at least 2 teeth with $5 \mathrm{~mm}$ or more of pocket depth in interproximal areas. On the other hand, severe periodontal disease is defined as having at least 2 teeth with loss of interproximal attachment or more and at least 1 tooth with $5 \mathrm{~mm}$ or more of pocket depth in interproximal regions.

Periodontal tissues generally show evidence of natural aging during the developmental process, where the degree of periodontal collapse increases with age. In this way, periodontal inflammation tends to progress rapidly, and tissues show a lower rate of healing [4,5].

The present study aims to reflect on the oral health status of the elderly, addressing the periodontal disease, as well as the importance of oral health, general health and quality of life.

\section{Materials and Methods}

The methodology adopted consisted of a bibliographic research of scientific articles indexed in PUBMED and Google Scholar with the following combined keywords: "Periodontal Disease", "Gerodontology", "Oral Health", "Elderly" and "Epidemiology", either in Portuguese or in English. The exclusion criteria for the selection of the scientific articles used consisted in limiting the research to the Portuguese and English languages, limiting the publication date to the last 10 years, and only scientific articles referring to the epidemiology 
of periodontal disease among the elderly. Therefore, from a total of 33 scientific articles, only 17 scientific articles were selected for the present research.

\section{Results and Discussion}

Most of the functional and oral tissue changes in age are considered secondary to extrinsic factors present throughout life $[6,7]$. The advancement of age is not, by itself, a determining factor with regard to functional and oral tissue changes, but rather the extrinsic factors that assume a preponderant role [6,7]. A decrease in medical and dental care as well as the neglect of oral hygiene are primary etiological factors and triggers the risk of oral disease development among the elderly [8].

Periodontal disease is one of the oral pathologies most frequently associated with tooth loss. Dental loss is a reality that in addition to oral problems has repercussions at a psychological and social level, which may reflect in terms of diet and general well-being of the individual [9].

The prevalence of edentulism in the elderly has been studied in several different populations ranging from 6 to $78 \%$ [6]. Fernandes JC et al. reports that, in a social institution of the district of Porto, in Portugal, there was a prevalence of $30.13 \%$ of total edentulism, predominantly among the female gender [10].

The dental loss is also related with smoking habits, low socioeconomic level and insufficient use of health care services [11].

Gingivitis is a reversible condition associated with the bacterial biofilm development that usually resolves clinically one week after the hygienic phase of periodontal treatment [12]. Ruiz Candina HJ et al. studied the prevalence of periodontal disease in individuals aged between 60 and 80 years, where in a sample of 65 individuals, 36 had gingivitis, corresponding to a prevalence of $55.38 \%$ [13].

\section{Aggressive periodontitis}

Aggressive periodontitis affects healthy individuals and is characterized by rapid and severe loss of bone-alveolar insertion [14]. Since its prevalence is higher in children and young adults, no epidemiological data have been found in the elderly.

\section{Mild, moderate and severe chronic periodontitis}

According to Bailey DL et al. mild chronic periodontitis is defined by the presence of one or more teeth with periodontal pocket $\geq 3 \mathrm{~mm}$ or one or more posterior teeth with grade 1 furcation involvement [15]. Moderate chronic periodontitis is defined as the presence of one or more teeth with a periodontal pocket $\geq 5 \mathrm{~mm}$ or one or more posterior teeth with grade 1 furcation involvement accompanied by periodontal pockets $\geq 3 \mathrm{~mm}$ [15].

Severe chronic periodontitis is defined as the presence of two or more teeth with a periodontal pocket $\geq 5 \mathrm{~mm}$ or four or more teeth with periodontal pockets $\geq 4 \mathrm{~mm}$ or one or more posterior teeth with grade 2 furcation involvement [15].

Demmer RT et al. compared several epidemiological studies on periodontal disease by analyzing the prevalence of mild, moderate and severe chronic periodontitis in different age groups [16]. Even in developed countries as the United States of America, Germany and Australia, the authors verified that the elderly presented considerable prevalence of moderate periodontitis between 24 and 55\% and severe periodontitis between 23 and $43 \%$. The incidence of the periodontitis disease was highly associated with the age increase among the elderly [16].

However, in a study developed in Germany, the prevalence of periodontal disease among the male gender aged 60 to 69 years old was $85 \%$ and decreased to $71 \%$ among elderly aged 70 to 79 years old. The same situation was verified among the female elderly: $71 \%$ in female elderly aged between 60 and 69 years old and a decrease to $62 \%$ in elderly aged between 70 and 79 years old [17].

\section{Conclusion}

The most recent studies do show that periodontal disease is clearly a public health issue, increasing among all ages. However, this oral pathology should be carefully analyzed among the elderly considering the higher risk of association with the development of other systemic diseases and also the physiological, mental and social changes that characterize this specific aging group. For instance, periodontal disease is highly associated with diabetes, being considered the sixth most higher complication associated with diabetes.

The epidemiological interpretation of periodontal data is difficult due to the scarcity of information and the inconsistency of the various methodologies applied. However, it can be verified that the prevalence of periodontal disease in the elderly patient is significant, although the trend is decreasing due to the fact that there are more oral health care and concerns, as well as greater access to medical and dental care.

\section{References}

1. Kandelman D, Petersen PE, Ueda H (2008) Oral health, general health, and quality of life in older people. Spec Care Dentist 28: 224-236.

2. Sousa L, Galante H, Figueiredo D (2003) Quality of life and well-being of elderly people: an exploratory study in the Portuguese population. J Public Health 37: 364-371.

3. Côrte-Real IS, Figueiral MH, Reis Campos JC (2011) Oral diseases in the elderly-general considerations. Port J Stomatol Dent Med Oral Maxillofac Surg 52: 175-180.

4. Xiong X, Buekens P, Fraser WD, Beck J, Offenbacher S (2006) Periodontal disease and adverse pregnancy outcomes: a systematic review. BJOG 113: 135-143.

5. Papapanou PN (2014) Commentary: advances in periodontal disease epidemiology: a retrospective commentary. J Periodontol 85: 877-879.

6. Kossioni AE, Dontas AS (2007) The stomatognathic system in the elderly. Useful information for the medical practitioner. Clin Interv Aging 2: 591-597.

7. Erić J, Tihaček Šojić L, Bjelović L, Tsakos G (2017) Changes in Oral Health Related Quality of Life (OHRQoL) and satisfaction with conventional complete dentures among elderly people. Oral Health Prev Dent 15: 237-244.

8. Yoshihara A, Watanabe R, Hanada N, Miyazaki H (2009) A longitudinal study of the relationship between diet intake and dental caries and periodontal disease in elderly Japanese subjects. Gerodontology 26: 130-136.

9. Ferreira RC, de Magalhães CS, Moreira AN (2008) Tooth loss, denture wearing and associated factors among an elderly institutionalised Brazilian population. Gerodontology 25: 168-178.

10. Fernandes JC (1995) Necessidades protéticas na população institucionalizada: contribuição para o seu estudo. Medisa - Edições e 
Citation: Veiga N, Monteiro C, Couto C, Silva D, Clemente L, et al. Epidemiology of Periodontal Disease among the Elderly. J Oral Biol. 2017 ; 4(2): 3.

\section{ISSN: 2377-987X}

Divulgações Científicas. Tese de Doutoramento. Faculdade de Medicina Dentária da Universidade do Porto.

11. Chalmers JM, Ettinger RL (2008) Public health issues in geriatric dentistry in the United States. Dent Clin North Am 52: 423-446.

12. Pihlstrom BL, Michalowicz BS, Johnson NW (2005) Periodontal diseases. Lancet 366: 1809-1820.

13. Ruiz Candina HJ, Batista AH (2009) The prevalence of periodontopathies and some risk factors in the elderly. Periodontal diseases prevalence and some risk factors present in the aged. Cuban J Biomed Res 28: 73-82.

14. Cortelli JR, Cortelli SC (2009) Periodontite Crônica E Agressiva: Prevalência
Subgengival E Freqüência De Ocorrência De Patógenos Periodontais. Rev Biociênc 9: 91-96.

15. Bailey DL, Barrow SY, Cvetkovic B, Musolino R, Wise SL, et al. (2016) Periodontal diagnosis in private dental practice: a casebased survey. Aust Dent J 61: 244-251.

16. Demmer RT, Papapanou PN (2010) Epidemiologic patterns of chronic and aggressive periodontitis. Periodontol 2000 53: 28-44.

17. Phipps KR, Chan BK, Jennings-Holt M, Geurs NC, Reddy MS, et al. (2009) Periodontal health of older men: the MrOS dental study. Gerodontology 26: 122-129. 